\title{
Doenças de equinos na região Sul do Rio Grande do Sul ${ }^{1}$
}

\author{
Clairton Marcolongo-Pereira ${ }^{2}$, Pablo Estima-Silva ${ }^{3}$, Mauro P. Soares ${ }^{4}$, Eliza Simone \\ V. Sallis ${ }^{4}$, Fabiane B. Grecco ${ }^{4}$, Margarida B. Raffi ${ }^{4}$, Cristina Gevehr Fernandes ${ }^{4}$ \\ e Ana Lucia Schild ${ }^{4 *}$
}

\begin{abstract}
Marcolongo-Pereira C., Estima-Silva P., Soares M.P., Sallis E.S.V., Grecco F.B., Fernandes C.G., Raffi M.B. \& Schild A.L. 2014. [Equine diseases in Southern Brazil.] Doenças de equinos na região Sul do Rio Grande do Sul. PesquisaVeterináriaBrasileira 34(3):205210. Laboratório Regional de Diagnóstico, Faculdade de Veterinária, Universidade Federal de Pelotas, Campus Universitário, Rua Gomes Carneiro 1, Pelotas, RS 96010-610, Brazil. E-mail: alschild@terra.com.br

A retrospective study of the diagnoses of injuries and deaths in equine in Southern Brazil was conducted between 1978 and 2012. All necropsy protocols and other materials of the Regional Diagnostic Laboratory of the Veterinary School of the Federal University of Pelotas were reviewed. The collected data consisted of 2,026 equine materials, including 514 necropsy protocols of and 1,512 other biologic materials, including the protocols of biopsies, organs, swabs, feces, blood, and skin scrapings. From the resulting 2,026 diagnoses, $467(23.05 \%)$ corresponded to neoplasms and tumor like lesions; 168 (8.29\%) to parasitic diseases; 135 (6.66\%) to bacterial diseases; 31 (1.53\%) to viral diseases; 86 (4.24\%) to diseases caused by fungi and oomycetes; $50(2.47 \%)$ to intoxication and poisoning by mycotoxins; $9(0.44 \%)$ to metabolic diseases; $60(2.96 \%)$ to other diseases; and $75(3.70 \%)$ to non-transmittable diseases of the digestive tract. Three hundred twenty cases $(15.79 \%)$ were classified as diseases of unknown etiology. Other diagnoses accounted for 489 of the total 2,026 cases (24.14\%). In 44 (8.56\%) of the 514 necropsies and 91 (9.47\%) of the 961 biopsies of organs mailed into the laboratory, the diagnoses were inconclusive, totaling $135(9.15 \%)$ of the 1,475 in the category. This study demonstrates the importance of skin lesions in horses, as $31.88 \%$ (642) of the biopsies received were lesions on the skin of the animals. The most significant tumors observed were equine sarcoid, at $33.18 \%$, and squamous cell carcinoma, at $7.94 \%$. The most common observed causes of death were leucoenceflomalacia (7.59\%), rabies (3.70\%) thromboembolism by Strongylus vulgaris $(2.33 \%)$ and monocytic ehrlichiosis (1.75\%).
\end{abstract}

INDEX TERMS: Horses, disease of horses, retrospective study, pathology.

RESUMO.- Foi realizado um estudo retrospectivo dos diagnósticos de causas de morte e de lesões em equinos na região Sul do Rio Grande do Sul entre 1978 e 2012. Foram revisados os protocolos de necropsia e materiais desta espécie encaminhados ao Laboratório Regional de Diagnós-

\footnotetext{
${ }^{1}$ Recebido em 19 de dezembro de 2013.

Aceito para publicação em 24 de fevereiro de 2014.

${ }^{2}$ Programa de Pós-Graduação em Veterinária, Bolsista de IC/CNPq, Faculdade de Veterinária (FV), Universidade Federal de Pelotas (UFPel), Campus Universitário, Pelotas, RS 96010-610, Brasil.

${ }^{3}$ Bolsista de IC/FAPERGS, FV-UFPel, Campus Universitário, Pelotas, RS 96010-610.

${ }^{4}$ Laboratório Regional de Diagnóstico, FV-UFPel, Campus Universitário, Pelotas, RS 96010-610.*Autor para correspondência: alschild@terra.com.br
}

tico da Faculdade de Veterinária da Universidade Federal de Pelotas no período. Foram recebidos 514 cadáveres de equinos e 1500 materiais (biopsias, órgãos, suabes, fezes, sangue e raspado de pele), totalizando 2026 materiais de equinos recebidos no período. Dos 2026 casos 467 $(23,05 \%)$ corresponderam a neoplasmas e lesões tumorifores, $168(8,29 \%)$ a doenças parasitárias; $135(6,66 \%)$ a doenças bacterianas, $31(1,53 \%)$ a doenças virais, 86 $(4,24 \%)$ a doenças causadas por fungos e oomicetos, 50 $(2,47 \%)$ a intoxicações e micotoxicoses, nove $(0,44 \%)$ a doenças metabólicas, $60(2,96 \%)$ a outras doenças e 75 $(3,70 \%)$ a doenças não transmissíveis do trato digestivo. Trezentos e vinte $(15,79 \%)$ foram classificados como doenças de etiologia indeterminada. Outros diagnósticos repre- 
sentaram 489/2026 (24,14\%) casos. Em 44/514 (8,56\%) das necropsias e em 91/961 (9,47\%) de biopsias e órgãos remetidos ao laboratório o diagnóstico foi inconclusivo, perfazendo um total de 135/1475 (9,15\%) casos incluídos nesta categoria. Ficou evidenciado neste trabalho a importância das lesões dermatológicas em equinos, sendo que $31,88 \%$ (642/2014) dos casos recebidos eram biopsias de lesões observadas na pele dos animais. Os principais tumores encontrados foram o sarcoide equino com 33,18\% e o carcinoma de células escamosas com 7,94\% das biopsias recebidas. Algumas causas de morte mais importantes diagnosticadas no período foram a leucoencefalomalacia $(7,59 \%)$, a raiva $(3,70 \%)$, o tromboembolismo por Strongylus vulgaris $(2,33 \%)$ e a erliquiose monocítica $(1,75 \%)$.

TERMOS DE INDEXAÇÃO: Equinos, doenças de equinos, estudo retrospectivo, patologia.

\section{INTRODUÇÃO}

O Rio Grande do Sul, cuja economia caracteriza-se pela produção integrada de agricultura-pecuária, possui uma população aproximada de 14.000 .000 de bovinos, de 3.900 .000 ovinos e de 453.000 equinos (IBGE 2010) e o conhecimento das enfermidades que ocorrem nessas espécies animais é fundamental para a determinação de sua importância econômica e o estabelecimento de medidas de controle das mesmas. Neste sentido os estudos retrospectivos, com a sistematização de dados obtidos por laboratórios de diagnóstico, principalmente aqueles que abrangem várias décadas, são importantes uma vez que permitem a determinação da frequência com que as doenças ocorrem, seus aspectos epidemiológicos e suas características clínico-patológicas (Pierezan et al. 2009).

Nos últimos anos, especialmente na região central do Estado, têm sido realizados estudos retrospectivos para a determinação da frequência e importância econômica das principais enfermidades de bovinos (Lucena et al. 2010), ovinos (Rissi et al. 2010) e equinos (Pierezan et al. 2009).

No estudo realizado em equinos por Pierezan et al. (2009) os autores observaram que as afecções do sistema digestivo foram as mais frequentes como causa de morte nesta espécie, similar ao observado em outro estudo realizado na Inglaterra (Baker \& Ellis 1981). No entanto, a prevalência das doenças pode diferir de um estudo para o outro (Pierezan et al. 2009). Na Paraíba o sistema nervoso central foi o mais frequentemente afetado levando a morte de equinos em um estudo de 159 casos (Pimentel et al. 2009).

De acordo com dados do Laboratório Regional de Diagnóstico da Faculdade de Veterinária da Universidade Federal de Pelotas (LRD/UFPel) os equinos representaram $10,14 \%$ de todas as espécies animais que chegaram ao laboratório entre 1978 e 2012, estando atrás apenas de bovinos e caninos (Schild et al. 2013) e na última década o número de necropsias/materiais de equinos processados no laboratório aumentou aproximadamente $70 \%$. Em razão disso, a sistematização dos dados do LRD/UFPel para essa espécie animal é fundamental e será útil para comparação com estudos realizados em outros laboratórios de diagnóstico detectando-se possíveis similaridades e/ou diferenças na ocorrência/frequência das diferentes enfermidades que afetam equinos, de acordo com características regionais por exemplo de solo, clima e/ou outros fatores epidemiológicos. Em estudos preliminares foi observado que algumas enfermidades como a erliquiose monocítica e a pitiose ocorrem com frequência em áreas úmidas e campos baixos sujeitos a alagamentos que é uma característica de alguns municípios da região sul do Rio Grande do Sul (Coimbra et al. 2006; Marcolongo-Pereira et al. 2012b).

Além disso, estão inseridos na região sul do Rio Grande do Sul os municípios de Bagé e Aceguá onde se instalaram há várias décadas diversos haras de criação de equinos da raça Puro Sangue Inglês e que nos últimos anos tem utilizado os serviços do LRD/UFPel para o diagnóstico de algumas enfermidades, especialmente às relacionadas com abortos e mortalidade perinatal.

Os objetivos do presente estudo foram identificar as principais enfermidades que ocorrem em equinos na região sul do Rio Grande do Sul destacando aquelas que causam a morte dos animais ou aquelas que determinam os maiores prejuízos econômicos.

\section{MATERIAL E MÉTODOS}

Foram pesquisados nos arquivos do Laboratório Regional de Diagnóstico da Faculdade de Veterinária da Universidade Federal de Pelotas (LRD/UFPel) os protocolos de necropsias realizadas no laboratório ou a campo e de materiais remetidos por veterinários de campo entre 1978 e dezembro de 2012. Foram resgatados os dados epidemiológicos obtendo-se informações referentes à procedência dos animais, tipo de criação, alimentação, idade, sexo, raça e função. Foram resgatados também, os sinais clínicos e evolução da enfermidade e a patologia macroscópica e histológica das necropsias ou biopsias/órgãos remetidos e os resultados de outros exames realizados. Os diagnósticos realizados foram agrupados em diferentes categorias de acordo com a natureza do agente etiológico, em neoplasmas e lesões tumoriformes, doenças parasitárias, doenças bacterianas, doenças virais, doenças causadas por fungos e oomicetos, intoxicações e micotoxicoses, doenças metabólicas, doenças não transmissíveis do trato digestivo e outras doenças. Os casos que não se enquadraram em nenhuma das etiologias mencionadas foram classificados como diagnósticos de etiologia indeterminada. Foram computados, também, os diagnósticos inconclusivos. Equinos ou materiais de equinos utilizados para experimentos foram excluídos.

\section{RESULTADOS}

Foram recebidos no LRD para análise, de janeiro de 1978 a dezembro de 2012, 514 cadáveres de equinos para necropsias e 1512 materiais de equinos [biopsias (642), órgãos (319), suabes (270), fezes (98), sangue (94) e raspados de pele (89)], totalizando 2026casos provenientes de municípios da área de influência do LRD/UFPel. Em 12 casos não havia informação do material remetido nos protocolos. Dos 2026 casos $467(23,05 \%)$ corresponderam a neoplasmas e lesões tumoriformes (Quadro 1), 168 (8,29\%) a doenças parasitárias (Quadro 2); $136(6,71 \%)$ a doenças bacterianas (Quadro 3), 31 (1,53\%) a doenças virais (Quadro 4), $86(4,24 \%)$ a doenças causadas por fungos e oomicetos (Quadro 4), 50 (2,47\%) a intoxicações e micotoxicoses 
Quadro 1. Neoplasmas e lesões tumoriformes (n=467) diagnosticados em equinos no Laboratório Regional de Diagnóstico da Faculdade de Veterinária da Universidade Federal de Pelotas entre janeiro de 1978 e dezembro de 2012

\begin{tabular}{|c|c|c|}
\hline $\begin{array}{l}\text { Neoplasmas e lesões } \\
\text { tumoriformes }\end{array}$ & $\begin{array}{l}\text { Número de casos/ } \\
\text { sítio anatômico }\end{array}$ & Total e \% \\
\hline Sarcoide & 213 - pele & $213(45,61)$ \\
\hline Tecido de granulação & 77 - pele & $77(16,49)$ \\
\hline $\begin{array}{l}\text { Carcinoma de células } \\
\text { escamosas }\end{array}$ & $\begin{array}{l}13 \text { - pele; } 9 \text { - vulva; } 12 \text { - pênis } \\
\text { e prepúcio; } 17 \text { - } \mathrm{DI}^{\mathrm{a}}\end{array}$ & $51(10,92)$ \\
\hline Papiloma & 31 - pele & $31(6,64)$ \\
\hline Fibroma & 10 - pele; 6 - DI & $16(3,43)$ \\
\hline Melanoma & $\begin{array}{l}6 \text { - pele; } 2 \text { - prepúcio; } \\
1 \text { - linfonodo; } 5 \text { - DI }\end{array}$ & $14(3,00)$ \\
\hline Fibrossarcoma & 8 - pele; 2 - DI & $10(2,14)$ \\
\hline Linfoma & $\begin{array}{l}5 \text { - pele; } 1 \text { - mediastino; } \\
1 \text { - rins e linfonodos; } 3 \text { - DI }\end{array}$ & $10(2,14)$ \\
\hline Lipoma & 4 - mesentério; 1 - DI & $5(1,07)$ \\
\hline $\begin{array}{l}\text { Tumor das células } \\
\text { da granulosa }\end{array}$ & 4 - ovário & $4(0,86)$ \\
\hline Carcinoma pulmonar & 3 - pulmão & $3(0,64)$ \\
\hline Hemangiossarcoma & 1-pele; 1 - intestino; 1 -DI & $3(0,64)$ \\
\hline Adenoma renal & $2-\operatorname{rim}$ & $2(0,43)$ \\
\hline Carcinoma renal & $2-\operatorname{rim}$ & $2(0,43)$ \\
\hline Hamartoma & 1 - pele; 1 - DI & $2(0,43)$ \\
\hline Hemangioma & 2 - pele & $2(0,43)$ \\
\hline Mastocitoma & 2 - pele & $2(0,43)$ \\
\hline Plasmocitoma & 1 - baço; 1 - DI & $2(0,43)$ \\
\hline Schwannoma & 1 - Pele; 1 - DI & $2(0,43)$ \\
\hline Adenoma da adrenal & 1 - adrenal & $1(0,21)$ \\
\hline Carcinoma de células basais & 1 - pele & $1(0,21)$ \\
\hline Carcinoma hepatocelular & 1 - fígado & $1(0,21)$ \\
\hline Carcinoma indiferenciado & $1-\mathrm{DI}$ & $1(0,21)$ \\
\hline Carcinoma nasal & 1 - cavidade nasal & $1(0,21)$ \\
\hline Carcinoma sólido de tireoide & 1 - tireoide & $1(0,21)$ \\
\hline Colesteatoma & 1 - encéfalo & $1(0,21)$ \\
\hline Lipossarcoma & 1 - pele & $1(0,21)$ \\
\hline Mesotelioma & 1 - mediastino & $1(0,21)$ \\
\hline $\begin{array}{l}\text { Mioblastoma de células } \\
\text { granulares }\end{array}$ & 1 - pulmão & $1(0,21)$ \\
\hline Nefroblastoma & $1-\operatorname{rim}$ & $1(0,21)$ \\
\hline Osteossarcoma & 1 - mandíbula & $1(0,21)$ \\
\hline Rabdomiosarcoma & 1- músculo estriado & $1(0,21)$ \\
\hline Sarcoma indiferenciado & 1 - pulmão & $1(0,21)$ \\
\hline Teratoma & 1 - ovário & $1(0,21)$ \\
\hline Tumor das células de Sertoli & 1 - testículo & $1(0,21)$ \\
\hline
\end{tabular}

${ }^{\mathrm{a}} \mathrm{DI}=$ dado indisponível.

(Quadro 4), nove $(0,44 \%)$ a doenças metabólicas (Quadro 4), $75(3,70 \%)$ a doenças não transmissíveis do trato digestivo (Quadro 5), e $60(2,96 \%)$ a outras doenças (Quadro 5). Trezentos e vinte casos $(15,79 \%)$ foram classificados como doenças de etiologia indeterminada. Outros diagnósticos incluindo autólise, culturas, esfregaços de sangue e fezes negativos a agentes bacterianos, a hematozoários e riquéticias e parasitas, respectivamente, representaram $489 / 2026(24,14 \%)$ casos. Em 44/514 (8,56\%) necropsias e em 91/961 (8,56\%) biopsias e órgãos remetidos ao laboratório o diagnóstico foi inconclusivo, perfazendo um total de 135/1475(9,15\%) casos incluídos nesta categoria.

Do total de materiais recebidos $974(48,08 \%)$ eram fêmeas e 663 (32,72\%) eram machos. Em 389 (19,20\%) casos não foi informado o sexo dos equinos.

A raça dos equinos foi informada em 1608 casos, sendo que $708(34,95 \%)$ eram equinos da raça Crioula, 454
Quadro 2. Doenças parasitárias (n=168) diagnosticadas em equinos no Laboratório Regional de Diagnóstico da Faculdade de Veterinária da Universidade Federal de Pelotas (LRD) entre janeiro de 1978 e dezembro de 2012

\begin{tabular}{lc}
\hline Doenças parasitárias & Número de casos (\%) \\
\hline Parasitose gastrintestinal $^{\mathrm{a}}$ & $83(49,40)$ \\
Habronemose & $29(17,26)$ \\
Piroplasmose & $21(12,50)$ \\
Tromboembolismo por Strongylusvulgaris & $12(7,14)$ \\
Erliquiosemonocítica & $9(5,36)$ \\
Mieloencefalite por protozoário $^{\text {Tripanossomíase }}{ }^{\mathrm{b}}$ & $4(2,38)$ \\
Aborto parasitário & $4(2,38)$ \\
Cisto hidático & $1(0,60)$ \\
Enterites por ciatostomíneos & $1(0,60)$ \\
Gasterofilose & $1(0,60)$ \\
Giardíase & $1(0,60)$ \\
Sarna psoróptica & $1(0,60)$ \\
\end{tabular}

a 74 correspondem a exames de fezes para controle parasitológico; ${ }^{\text {bSurtos }}$ ocorridos fora da área de Influência do LRD (Rodrigues et al. 2005).

Quadro 3. Doenças bacterianas $(n=136)$ observadas em equinos pelo Laboratório Regional de Diagnóstico da Faculdade de Veterinária da Universidade Federal de Pelotas entre janeiro de 1978 a dezembro de 2012

\begin{tabular}{|c|c|}
\hline Doenças bacterianas & Número de casos (\%) \\
\hline Aborto & $27(19,85)$ \\
\hline Endometrite & $25(18,38)$ \\
\hline Dermatofilose & $14(10,29)$ \\
\hline Leptospirose & $12(8,82)$ \\
\hline Rodococose & $10(7,35)$ \\
\hline Tétano & $9(6,62)$ \\
\hline Brucelose & $7(5,15)$ \\
\hline Guturocistite & $5(3,68)$ \\
\hline Edema maligno & $5(3,68)$ \\
\hline Broncopneumonia por Streptococcusequi & $3(2,21)$ \\
\hline Cistite & $3(2,21)$ \\
\hline Nefrite & $2(1,47)$ \\
\hline Pneumonias & $2(1,47)$ \\
\hline Salmonelose & $2(1,47)$ \\
\hline Poliartrite por Streptococcus $\alpha$ hemolítico & $1(0,74)$ \\
\hline Abscesso cerebral por Corynebacteriumequum & $1(0,74)$ \\
\hline Abscesso por Streptococcusequizooepidemicus & $1(0,74)$ \\
\hline Abscesso por Streptococcus $\beta$ hemolítico & $1(0,74)$ \\
\hline Bursite por Staphylococcus sp. & $1(0,74)$ \\
\hline Conjuntivite & $1(0,74)$ \\
\hline Mastite por Pseudomonas sp. & $1(0,74)$ \\
\hline Pleurite por Streptococcus $\beta$ hemolítico & $1(0,74)$ \\
\hline Pododermatite por Protheus sp. & $1(0,74)$ \\
\hline Rinite & $1(0,74)$ \\
\hline
\end{tabular}

(22,41\%) sem raça definida, 373 (18,41\%) Puro Sangue Inglês, 19 (0,94\%) Quarto-de-milha, 16 (0,79\%) Pônei, 16 $(0,79 \%)$ Árabes, nove $(0,44 \%)$ Percheron, cinco $(0,25 \%)$ Appaloosa, quatro $(0,20 \%)$ Mangalarga marchador, dois $(0,10 \%)$ Brasileiro de hipismo, um $(0,05 \%)$ Bretão e um $(0,05 \%)$ Hannoverano. Em 418 casos $(20,66 \%)$ a raça não estava informada nos protocolos.

Os equinos tinham até um ano de idade em 221 $(10,91 \%)$ casos, em $415(20,48 \%)$ entre dois e cinco anos, em $388(19,15 \%)$ entre seis e dez anos, em 138 (6,81\%) entre 11 e 15 anos e em 108 (5,33\%) tinham idade acima de 16 anos. Em 756 (37,31\%) protocolos a idade dos equinos não foi informada. 
Quadro 4. Doenças virais, doenças causadas por fungos e oomicetos, intoxicações e micotoxicoses, doenças metabólicas e outras doenças $(n=236)$ diagnosticadas em equinos no Laboratório Regional de Diagnóstico da

Faculdade de Veterinária da Universidade Federal de Pelotas (LRD) entre janeiro de 1978 e dezembro de 2012

\begin{tabular}{|c|c|}
\hline Doenças virais & Número de casos $n=31(\%)$ \\
\hline Raiva & $19(61,29)$ \\
\hline Anemia Infecciosa Equina & $5(16,13)$ \\
\hline Aborto viral & $4(12,90)$ \\
\hline Influenza equina & $1(3,23)$ \\
\hline Molluscumcontagiosum & $1(3,23)$ \\
\hline Rinopneumonite equina & $1(3,23)$ \\
\hline Doenças causadas por fungos e oomicetos & Número de casos $n=86(\%)$ \\
\hline Pitiose & $66(76,74)$ \\
\hline Dermatofitose & $12(13,95)$ \\
\hline Rinosporidiose & $7(8,14)$ \\
\hline Candidose & $1(1,16)$ \\
\hline Toxicoses & Número de casos $n=50(\%)$ \\
\hline Leucoencefalomalacia & $39(78,00)$ \\
\hline Intoxicação por Bacchariscoridifolia & $4(8,00)$ \\
\hline Intoxicação por Clavicepspurpúrea & $2(4,00)$ \\
\hline Intoxicação por Senecio sp. & $2(4,00)$ \\
\hline Aborto por Ateleiaglazioviana ${ }^{\mathrm{a}}$ & $1(2,00)$ \\
\hline Intoxicação por antibióticos ionóforos & $1(2,00)$ \\
\hline Intoxicação por ureia & $1(2,00)$ \\
\hline Doenças metabólicas & Número de casos $n=9(\%)$ \\
\hline Osteodistrofia fibrosa & $8(88,89)$ \\
\hline Rabdomiólise & $1(11,11)$ \\
\hline
\end{tabular}

Quadro5. Doenças não transmissíveis do trato digestivo $(n=75)$ e outras doenças $(n=60)$ diagnosticadas em equinos no Laboratório Regional de Diagnóstico da Faculdade de Veterinária da Universidade Federal de Pelotas entre janeiro de 1978 e dezembro de 2012

\begin{tabular}{lc}
\hline Doenças não transmissíveis do trato digestivo & Número de casos (\%) \\
Caquexia & $19(25,33)$ \\
Dilatação gástrica com ruptura & $10(13,33)$ \\
Ruptura traumática do intestino & $8(10,67)$ \\
Obstrução intestinal por corpo estranho & $7(9,33)$ \\
Torção do intestino delgado & $7(9,33)$ \\
Cólica & $3(4,00)$ \\
Colite X & $3(4,00)$ \\
Deslocamento do cólon maior & $3(4,00)$ \\
Dilatação gástrica sem ruptura & $2(2,67)$ \\
Encarceramento de alça intestinal & $2(2,67)$ \\
Impactação do cólon maior & $2(2,67)$ \\
Intussuscepção ceco-cólica & $2(2,67)$ \\
Úlceras gástricas & $2(2,67)$ \\
Deslocamento do ceco & $1(1,33)$ \\
Impactação do ceco & $1(1,33)$ \\
Impactação gástrica & $1(1,33)$ \\
Intussuscepção do cólon & $1(1,33)$ \\
Úlcera esofágica & $1(1,33)$ \\
Outras doenças & 1 Número de casos $(\%)$ \\
Fratura & $37(61,67)$ \\
Mielopatia cervical estenótica & $9(15,00)$ \\
Ruptura uterina & $3(5,00)$ \\
Acidente ofídico & $2(3,33)$ \\
Fulguração & $2(3,33)$ \\
Aplasia de ducto mesonéfrico & $1(1,67)$ \\
Artrogripose & $1(1,67)$ \\
Hérnia diafragmática & $1(1,67)$ \\
Hidrocefalia & $1(1,67)$ \\
Hipoplasia cerebelar & $1(1,67)$ \\
Ruptura de bexiga & $1(1,67)$ \\
Ruptura de ligamento & $1(1,67)$ \\
&
\end{tabular}

\section{DISCUSSÃO}

Ficou evidenciado neste trabalhoa importância das lesões dermatológicas em equinos. Deve ser considerado que $31,85 \%(642 / 2026)$ dos casos recebidos no laboratório eram biopsias de lesões observadas na pele dos animais. Destas 55,92\% (359/642) eram neoplasmas e 11,99\% (77/642) eram tecido de granulação. As lesões de pele afetam principalmente a estética dos equinos (Souza et al. 2011), e determinam queda no valor comercial desta espécie em exposições e feiras. Percentuais de 50\% (Baker \&Leyland 1975) e 77,6\% (Souza et al. 2011) de tumores de pele tem sido diagnosticados em outros estudos restrospectivos de enfermidades de equinos.

Em um trabalho realizado na região central do Rio Grande do Sul as lesões tumoriformes e neoplasmas representaram $6,56 \%$ dos casos, no entanto, nesse trabalho foram estudadas somente as causas de morte em equinos (Pierezan et al. 2009).

As parasitoses gastrintestinais representaram praticamente metade dos casos de doenças parasitárias observadas no LRD no período estudado, no entanto deve considerar-se aqui que a maioria destes diagnósticos foi realizada em fezes de equinos, sendo considerada apenas a contagem de ovos. Habronemose cutânea foi a segunda parasitose mais importante observada em equinos da região representando 17,26\% (29/168) dos casos. Aparentemente, os casos de habronemose caíram drasticamente após a utilização das ivermectinas como drogas anti-helmínticas (Scott \& Miller Jr. 2011). Por outro lado, no presente estudo o maior número de diagnósticos de habronemose cutânea ocorreu a partir do ano 2000 até 2012. Provavelmente, o aumento na casuística dessa enfermidade tenha ocorrido em consequência do grande número de materiais enviados ao laboratório suspeitos de pitiose, que é endêmica na região (Marcolongo-Pereira et al. 2012b) e confundível com habronemose. Além disso, a partir do ano 2000 aumentou muito o envio de materiais e cadáveres desta espécie animal ao LRD/UFPel em consequência da ampliação do atendimento no Hospital Veterinário/FV/UFPel. Cabe destacar que entre 1978 e 1999 foram recebidos no laboratório 733 materiais de equinos e entre 2000 e 2012 foram recebidos 1293 representando um aumento de $76,4 \%$.

0 diagnóstico de piroplasmose equina foi realizado na grande maioria dos casos em amostras de sangue enviadas ao laboratório. Em apenas cinco oportunidades o diagnóstico foi feito durante necropsias. Em um trabalho realizado no sul do Rio Grande do Sul, foi demonstrado que a população de equinos na região está exposta a infecção por Theileriaequi e Babesia caballi e que a piroplasmose equina está disseminada na região e é uma das mais importantes doenças parasitárias em cavalos (Nizole et al. 2008, Torres et al. 2012).

Erliquiose monocítica foi diagnosticada nos municípios de Arroio Grande, Pelotas e Rio Grande em propriedades com áreas alagadiças próximas as Lagoas dos Patos e Mirim. A doença foi estudada anteriormente e considerada endêmica na região com uma morbidade de $26 \%$ e letalidade de 46,1\% (Coimbra et al. 2006). No que se refere a 
mieloencefalite por protozoário quatro casos apresentaram lesões compatíveis com a enfermidade no período estudado. Um trabalho de diagnóstico pela análise do líquido cefalorraquidiano por westernblot em equinos da região da Campanha e da região Sul do Rio Grande do Sul demonstrou uma prevalência da doença de $29,5 \%$, porém tem sido constatado que em aproximadamente $61 \%$ dos casos o tratamento é eficiente e os equinos se recuperam (Lins et al. 2012), o que pode explicar o pequeno número de casos que chega para necropsia no LRD/UFPel.

As demais enfermidades parasitárias diagnosticadas no LRD/UFPel tiveram baixa frequência e tem pouca importância como causa de morte ou de prejuízos econômicos para a criação de equinos na região. Chama a atenção um caso de hidatidose diagnosticado em um equino proveniente do município de Piratini. Esta doença é rara em equinos e não havia sido diagnosticada previamente no Brasil, ocorrendo em consequência de uma cepa equino-específica de Echinococcus granulosus (Ruas et al. 1997), reclassificada, posteriormente, como Echinococcus equinus (Thompson \&McManus, 2002).

Com relação às doenças bacterianas observou-se que as principais estão relacionadas à reprodução e por esta razão causam prejuízos econômicos importantes especialmente em haras de criação de equinos PSI. Num estudo realizado no Sul do Rio Grande do Sul entre 2000 e 2011 abortos devidos a causas bacterianas representaram $68,4 \%$ dos casos, sendo Klebisiella pneumoniae, Leptospira sp. e Streptococcus beta hemolítico as bactérias mais frequentes (Marcolongo-Pereira et al. 2012a).

Com relação às doenças virais a raiva representou 2,28\% (19/514) das causas de morte em equinos na região e foi a principal enfermidade dentre as virais diagnosticadas. Tem sido mencionado que a raiva em equinos é pouco estudada no Brasil (Lima et al. 2005). Foi observado que a raiva a partir de 2008 afetou um grande número de bovinos sendo registrados 72 surtos até 2012 nesta espécie (Schild et al. 2013). Em equinos foram registrados 10 casos no mesmo período. Por outro lado, o baixo número de casos confirmados dessa enfermidade poderia ser devido ao não envio de amostras ao laboratório (Pedroso et al. 2010). Aparentemente, no presente estudo o percentual de casos de raiva está relacionado à população desta espécie nas propriedades onde ocorreram os surtos.

Pitiose é uma doença frequente na região sul do Rio Grande do Sul devido às condições epidemiológicas favoráveis à presença do agente Pythium insidiosum (Marcolongo Pereira et al. 2012b). No presente trabalho esta enfermidade foi a terceira mais frequentemente observada na pele de equinos e apesar de não ser uma causa de morte expressiva torna-se importante pelos prejuízos estéticos aos animais já que o tratamento mais eficiente é o cirúrgico logo que as lesões são observadas, em geral nos membros, na face e na região ventral (Leal et al. 2001).

Dentre as intoxicações e micotoxicoses em equinos destaca-se a leucoencefalomalacia representando 7,58\% (39/514) das causas de morte em equinos na região. Em um trabalho realizado na região central do Rio Grande do Sul a leucoencefalomalacia representou $2,38 \%$ das causas de morte em equinos, sendo a mais importante das doenças neurológicas nesta espéciecom $20 \%$ dos casos (Pierezanet al. 2009). No presente trabalho chama atenção que a grande maioria dos casos foi diagnosticada até o ano 1999. Isto aparentemente deve-se ao fato de que por conhecerem a micotoxicose, veterinários e proprietários passaram a evitar a alimentação de equinos com milho ou rações contendo este cereal, o que diminuiu consideravelmente os casos de intoxicação.

Osteodistrofia fibrosa representou 1,56\% (8/514) das causas de eutanásia em equinos. Percentual semelhante foi encontrado em um estudo na região central do Estado (Pierezan et al. 2009). Todos os casos diagnosticados no presente estudo ocorreram em equinos de tração da área urbana que frequentemente são alimentados com farelo de milho ou milho inteiro determinando o desequilíbrio na relação cálcio e fósforo. Em consequência dessa enfermidade foram observadas fraturas nas costelas, sesamoides, e na maioria dos casos aumento de volume da face.

Com relação às doenças não transmissíveis do trato digestivo a caquexia, embora seja uma condição física e não uma enfermidade propriamente dita, representou 3,69\% das causas de morte em equinos. A maioria destes casos ocorreu em animais de tração que são criados ao redor da zona urbana do município e seguidamente sofrem abandono e maus tratos e são encaminhados para necropsia. Em outro estudo a caquexia representou $1,19 \%$ das causas de morte em equinos (Pierezan et al. 2009).

A cólica é uma condição multifatorial que pode originar-se nos órgãos digestivos ou em outros órgãos abdominais (Godoy \& Neto 2007). No presente estudo o diagnóstico de cólica representou 0,58\% (3/514), no entanto este percentual refere-se apenas aos casos em que os equinos tinham sinais de cólica, porém a causa da mesma não foi identificada. Se considerarmos os diagnósticos das outras enfermidades que causaram cólica e levaram os animais a morte este percentual passa para $12,8 \%(53 / 514)$. Tem sido mencionado que a cólica é uma das maiores causas de morte de equinos se não tratada, podendo atingir uma prevalência de $10 \%$ em uma população desta espécie animal (White 1995).

0 número de casos inconclusivos do total de cadáveres recebidos para necropsia foi similar ao encontrado em estudos similares realizados na região central do Rio Grande do Sul (Pierezan et al. 2009) e no Nordeste do Brasil (Pimentel et al. 2009).

\section{REFERÊNCIAS}

Baker J.R. \& Ellis C.E. 1981. A survey of post mortem findings in 480 horses from 1958 to 1980: Causes of death. Equine Vet. J. 13(1):43-46.

Baker J.R. \& Leyland A. 1975.Histological survey of tumours of the horse, with particular reference to those of the skin.Vet. Rec. 96:419-422.

Coimbra H.S., Fernandes C.G., Soares M.P., Meireles M.C.A., Radamés R. \& Schuch L.F.D. 2006. Erliquiosemonocítica equina no Rio Grande do Sul: aspectos clínicos, anátomo-patológicos e epidemiológicos. Pesq. Vet. Bras. 26(2):97-101.

Godoy R.F. \& Neto A.R.T. 2007. Cólica em equinos, p.571-621. In: Riet-Correa F., Schild A.L., Lemos R.A.A. \& Méndez M.C. (Eds), Doenças de Ruminantes e Equinos. Vol.2. 3a ed. Varela, São Paulo. 694p.

IBGE 2010. Produção da Pecuária Municipal, 2009. Instituto Brasileiro de 
Geografia e Estatística. Disponível em <http://www.ibge.gov.br/home/ estatistica/economia/ppm/2009/ default_pdf.shtm> http://www.ibge. gov.br/home/estatistica/economia/ppm/2009/ default_pdf.shtmAcesso em 8 set. 2011.

Kerr K.M. \& Alden C.L. 1974. Equine neoplasia: a ten year survey. Proc. Am. Assoc. Vet. Lab. Diagn. 17:183-187.

Ladeira S.R.L., Ruas J.L., Soares M.P. \& Schild A.L. 2012. Boletim do Laboratório Regional de Diagnóstico: doenças diagnosticadas no ano de 2011. Editora e Gráfica Universitária, Pelotas. 50p.

Leal A.B.M., Leal A.T., Santurio J.M., Kommers G.D. \& Catto J.B. 2001. Pitioseeqüina no Pantanal brasileiro: aspectos clínico-patológicos de casos típicos e atípicos. Pesq. Vet. Bras. 21(4):151-156.

Lima E.F., Riet-Correa F., Castro R.S., Gomes A.A.B. \& Lima F.S. 2005. Sinais clínicos, distribuiçãodas lesões no sistema nervoso e epidemiologia da raiva em herbívoros na região Nordeste do Brasil. Pesq. Vet. Bras. 25:250-264.

Lins L.A., Feijó L.S. \& Nogueira C.E.W. 2012. Mieloencefaliteprotozoária equina nas regiões da Campanha e do sul do Rio Grande do Sul no período de 1998-2006. Revta Ciênc. Agrovet. 11(3):248-250.

Lucena R.B., Pierezan F., Kommers G.D., Irigoyen L.F., Fighera R.A. \& Barros C.S.L. 2010. Doenças de bovinos no sul do Brasil: 6.706 casos. Pesq. Vet. Bras. 30(5):428-434.

Marcolongo-Pereira C., Adrien M.L., Ladeira S.R.L., Soares M.P., Assis-Brasil N.D. \& Schild A.L. 2012a. Abortos em equinos na região sul do Rio Grande do Sul: estudo de 72 casos. Pesq. Vet. Bras. 32(1):22-26.

Marcolongo-Pereira C., Sallis E.S.V., Raffi M.B., Pereira D.I.B., Hinnah F.L., Coelho A.C.B. \& Schild A.L. 2012b. Epidemiologia da pitiose equina na Região Sul do Rio Grande do Sul. Pesq. Vet. Bras. 32(9):865-868.

Nizoli L.Q., Götze M.M., Félix S.R., Silva S.S. \& Nogueira C.E.W. 2008. Frequency of seropositive equines for Theileria equi in the Southern Rio Grande do Sul State, Brazil. Parasitol. Latinoam. 63:46-50.

Pedroso P.M.O., Colodel E.M., Gomes D.C., Varaschin M.S., Bezerra Júnior P.S., Barbosa J.D., Tokarnia C.H. \& Driemeier D. 2010. Aspectos clínicopatológicos e imuno-histoquímicos de equídeos infectados pelo vírus da raiva. Pesq. Vet. Bras. 30(11):909-914.

Pierezan F., Rissi D.R., Rech R.R., Fighera R.A., Brum J.S. \& Barros C.S.L.
2009. Achados de necropsia relacionados com a morte de 335 equinos: 1968-2007. Pesq. Vet. Bras. 29(3):275-280.

Pimentel L.A., Oliveira D.M., Galiza G.J.N., Rego R.O., Dantas A.F.M. \& Riet-Correa F. 2009. Doenças do sistema nervoso central de equídeos no semi-árido. Pesq. Vet. Bras. 29(7):589-597.

Rissi D.R., Pierezan F., Oliveira Filho J.C., Fighera R.A., Irigoyen L.F., Kommers G.D. \& Barros C.S.L. 2010. Doenças de ovinos da região Central do Rio Grande do Sul: 361 casos. Pesq. Vet. Bras. 30(1):21-28.

Rodrigues A., Fighera R.A., Souza T.A., Schild A.L., Soares M.P., Milano J. \& Barros C.S.L. 2005. Surtos de tripanossomíase por Trypanosoma evansi em equinos no Rio Grande do Sul: aspectos epidemiológicos, clínicos, hematológicos e patológicos. Pesq. Vet. Bras. 25:239-249.

Ruas J.L., Schild A.L., Fernandes C.G., Ferreira J.L.M. \& Müller G. 1997. Cerebral equine hydatidosis in Southern Brazil. Ciência Rural 27(2):341344.

Schild A.L., Marcolongo-Pereira C., Fiss L., Santos B.L. \& Sallis E.S.V. 2013. Doenças diagnosticadas pelo Laboratório Regional de Diagnóstico no ano de 2012 e comentários sobre algumas doenças. Boletim do Laboratório Regional de Diagnóstico 35, Pelotas. 63p.

Scott D.W. \& Miller Jr W.H. 2011. Equine Dermatology. $2^{\text {nd }}$ ed. Elsevier Saunders, Maryland Heights, Missouri, 552p.

Souza T.M., Brum J.S., Fighera R.A., Brass K.E. \& Barros C.S.L. 2011. Prevalência dos tumores cutâneos de equinos diagnosticados no Laboratório de Patologia Veterinária da Universidade Federal de Santa Maria, Rio Grande do Sul. Pesq. Vet. Bras. 31(5):379-382.

Thompson R.C.A. \& McManus D.P. 2002. Towards a taxonomic revision of the genus Echinococcus. Trends Parasitol. 18(10):452-457.

Torres A.J., Finger I.S., Farias N.A.R., Nizoli L.Q., Silva S.S. \& Nogueira C.E.W. 2012. Aspectos epidemiológicos da Theileriose equina e sua relação com o carrapato Rhipicephalus (Boophilus) microplus em duas propriedades na região da campanha do Rio Grande do Sul, Brasil. Revta IberoLatinoam. Parasitol. 71(1):70-77.

Valentine B.A. 2006. Survey of equine cutaneous neoplasia in the Pacific Northwest. J. Vet. Diagn. Invest. 18:123-126.

White N.A. 1995. Epidemiology of equine colic. Anais $2^{\circ}$ Ciclo Internacional de Cólica Equina, Jaboticabal, SP, p.1-9. 